\title{
Changing trends in the incidence of caesarean section after a district hospital became medical college teaching hospital at Karwar, a coastal city in Karnataka-an eleven years retrospective audit
}

\author{
Somashekharappa B. Kadur ${ }^{1 *}$, Annappa. B. Shetty ${ }^{2}$
}

\begin{abstract}
${ }^{1}$ Department of Anaesthesiology, ${ }^{2}$ Department of Obstetrics and Gynaecology, Karwar Institute of Medical Sciences, Karwar, Karnataka, India
\end{abstract}

Received: 06 April 2021

Accepted: 13 May 2021

\author{
*Correspondence: \\ Dr. Somashekharappa B. Kadur, \\ E-mail: smkdr69@gmail.com
}

Copyright: (c) the author(s), publisher and licensee Medip Academy. This is an open-access article distributed under the terms of the Creative Commons Attribution Non-Commercial License, which permits unrestricted non-commercial use, distribution, and reproduction in any medium, provided the original work is properly cited.

\begin{abstract}
Background: Caesarean section (C-section) delivery has well established risks and adverse consequences. Every health care sector should look into the standards of maternal services it is providing. This audit look into the standards we have been providing at KRIMS Karwar with a comparison to national standards.

Methods: This is a retrospective audit conducted by obstetrics and anaesthesia departments at KRIMS Karwar, Karnataka. Objectives were to look into incidence of C-sections, kind of anaesthesia used and maternal mortality. In addition, to look into any change in the obstetric care/outcome after Karwar district general hospital upgraded to a medical college teaching hospital. WHO guidelines for obstetrics care were set as standards. Retrospective data for the period between January 2007 and December 2018 has been collected and analysed.

Results: Total number of pregnant women admitted for labour was 13431 with an average of 1221 per year. Proportion of caesarean delivery per hundred labouring women was $16.8 \%$ in 2007 with significant increase to reach $51 \%$ in 2012 . This has decreased in subsequent years to reach 23.5 in $2018.99 .9 \%$ of the C-sections have been done under spinal anaesthesia. There was one death of the mother subjected for C-sections in 2009.

Conclusions: Incidence of C-sections was alarmingly high. Implementation of the uniform protocol has significantly reduced the $\mathrm{C}$-sections rate. This reduction could be attributed to the upgrading the Karwar district hospital to a medical college teaching hospital. Protocol based practice will be continued and measures to improve overall maternity services will be implemented as per the WHO guidelines.
\end{abstract}

Keywords: C-section, Obstetrics anaesthesia, WHO guidelines

\section{INTRODUCTION}

Mother and child health is a vital parameter in assessing the overall health care standard of a society. Health and family welfare department of India has framed guidelines to improve the safety standards for mother and child health. ${ }^{1}$ These guidelines are based on WHO recommendations. $^{2}$ The RCOG protocols say the incidence of C-section should not exceed $20 \%$ in a tertiary care hospital with average annual labour ward admission of 2000 pregnant women. ${ }^{3}$ An increased focus on standard of care during childbirth can lead to reductions in disability, maternal and neonatal mortality and stillbirths. ${ }^{4}$ Present day concern is about decision making in considering labouring mothers for $\mathrm{C}$-section and the rising number of them. Every health care sector should look into the maternal service it is providing and compare its outcome to the national guidelines in order to know the deficits and implement measures to correct them. Karwar district hospital in Karnataka state, India, is upgraded to a teaching hospital after starting the Karwar institute of medical sciences (KRIMS) in 2015. 
Department of obstetrics and gynaecology in collaboration with anaesthesiology of KRIMS Karwar has made an attempt to analyse retrospectively the maternity and anaesthesia services for the last eleven years (2007-2018) and compared the results to the national standards.

\section{METHODS}

This is a retrospective audit conducted by obstetrics and anaesthesia departments at KRIMS Karwar, Karnataka. Objectives of this audit are to look into the incidence of C-sections, kind of anaesthesia used, maternal mortality for the last 10 years from January 2007 until December 2018. And also, to look into any change in the obstetric care/outcome after Karwar district hospital upgraded to a medical college teaching hospital. We set WHO guidelines for obstetrics care as standards to compare the audit results. Inclusion criteria were to include all the mothers scheduled for C-sections during the ten-year audit period. Mothers whose medical records were not available or incomplete were excluded from the audit. The audit team visited the medical record section of the hospital and collected the required data of maternity and anaesthesia services provided at KRIMS hospital (District hospital Karwar before 2015) during the period between January 2007 and December 2018. This team has collected data related to number of women in labour, Csections, kind of anaesthesia used, maternal death (Table 1). For the convenience of understanding team has collected and presented the data on yearly basis for 10 years. This has been analysed and the results were compared to the standards. Ethics committee approval was not needed since this audit procedure doesn't involve patients directly but only their medical records.

\section{RESULTS}

In the eleven years of audit duration, total number of pregnant women admitted at KRIMS Karwar hospital for labour was 13431 with an average of 1221 per year (Table 1).

Table 1: Audit (retrospective) data.

\begin{tabular}{|c|c|c|c|c|c|c|c|}
\hline Year & $\begin{array}{l}\text { No. of women } \\
\text { in labour }\end{array}$ & No. of CS & $\begin{array}{l}\% \text { of } \\
\mathrm{CS}\end{array}$ & $\begin{array}{l}\text { Spinal } \\
\text { anaesthesia }\end{array}$ & $\begin{array}{l}\text { General } \\
\text { anaesthesia }\end{array}$ & $\begin{array}{l}\text { Maternal } \\
\text { death }\end{array}$ & Complications \\
\hline 2007 & 1122 & 189 & 16.8 & 189 & 0 & 0 & 0 \\
\hline 2008 & 1080 & 269 & 24.9 & 268 & 1 & 0 & 0 \\
\hline 2009 & 1176 & 297 & 25.25 & 297 & 0 & 1 & 0 \\
\hline 2010 & 986 & 273 & 27.6 & 273 & 0 & 0 & 0 \\
\hline 2011 & 960 & 345 & 35.9 & 345 & 0 & 0 & 0 \\
\hline 2012 & 820 & 419 & 51 & 419 & 0 & 0 & 0 \\
\hline 2013 & 1395 & 470 & 33.9 & 470 & 0 & 0 & 0 \\
\hline 2014 & 1347 & 425 & 31.5 & 425 & 0 & 0 & 0 \\
\hline 2015 & 1413 & 351 & 24.8 & 351 & 0 & 0 & 0 \\
\hline 2016 & 1490 & 313 & 21 & 313 & 0 & 0 & 0 \\
\hline 2017 & 1483 & 346 & 23.3 & 345 & 1 & 0 & 0 \\
\hline 2018 & 999 & 235 & 23.5 & 233 & 2 & 0 & 0 \\
\hline Total & 13431 & 3932 & & 3928 & 4 & 1 & 0 \\
\hline
\end{tabular}

In the beginning of the audit period the number of women admitted for labour was around 1000 per year. From the year 2013 we notice a raise in the number reaching a maximum of 1490 in 2016 and have decreased to 999 in the year 2018 (Figure 1).

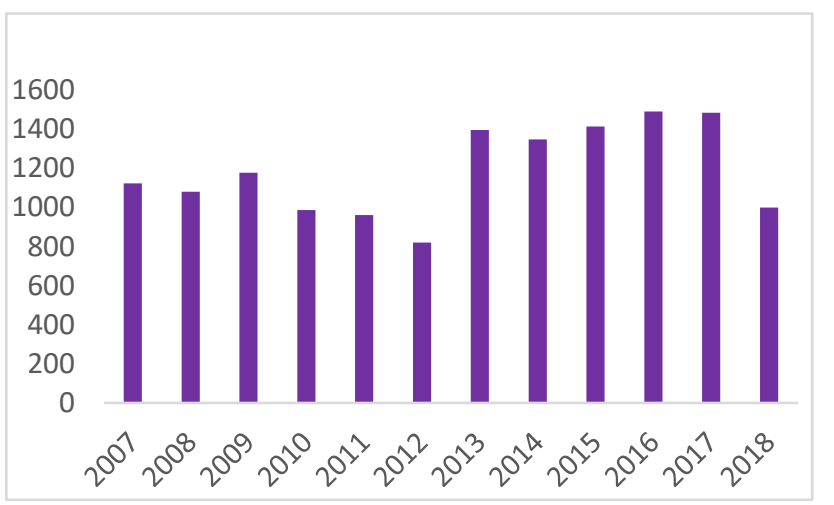

Figure 1: Number of women in labour.
Number of C-Section delivery has increased from 189 in 2007 to 273 in 2010 followed by a rapid rise to 470 in 2013. This incidence has gradually decreased to reach 235 in the year 2018 (Figure 2).

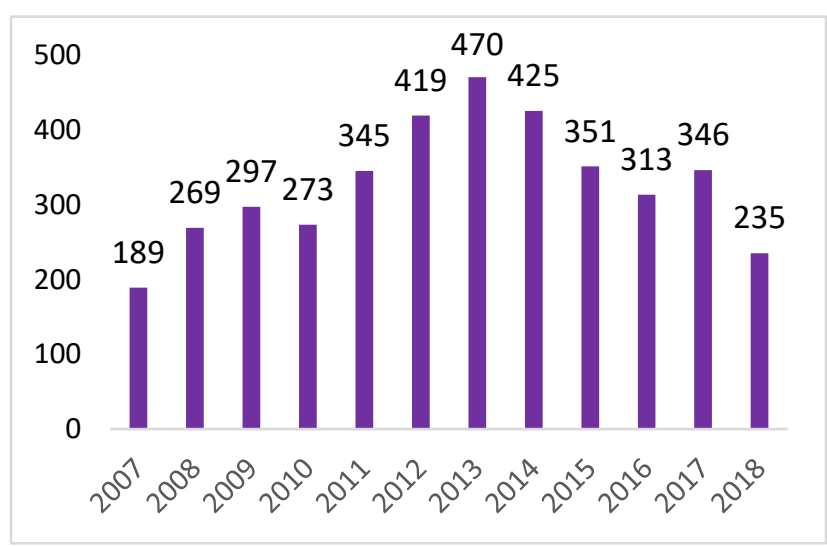

Figure 2: Number of C-sections. 
Proportion of caesarean delivery per hundred labouring women was $16.8 \%$ in 2007 which has increased to $51 \%$ in 2012. Then we observed a gradual decrease in this trend to reach $23.5 \%$ in 2018 (Figure 3).

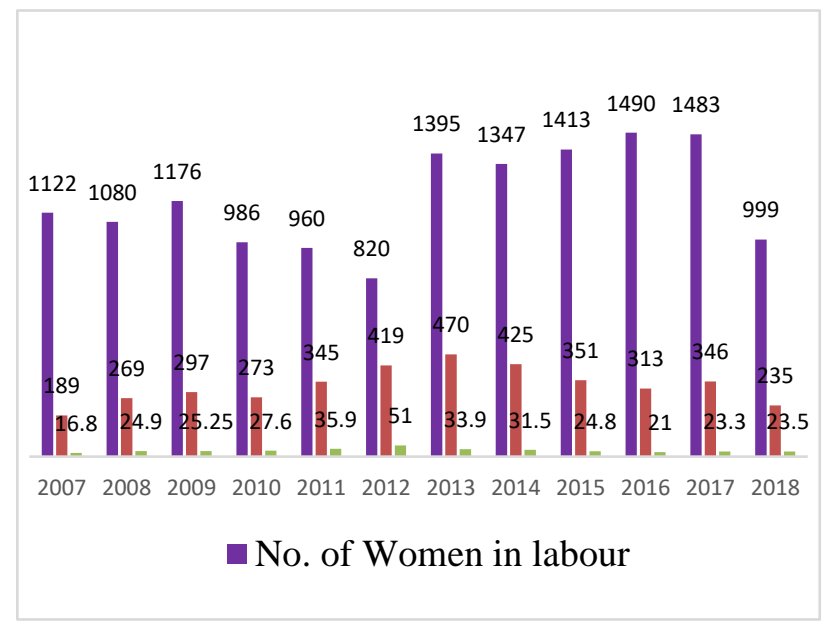

Figure 3: Correlation between number of labouring women and rate of $\mathrm{C}$-section.

Out of 3932 C-sections only 4 cases were done under general anaesthesia and remaining 3928 cases under spinal anaesthesia (Figure 4).

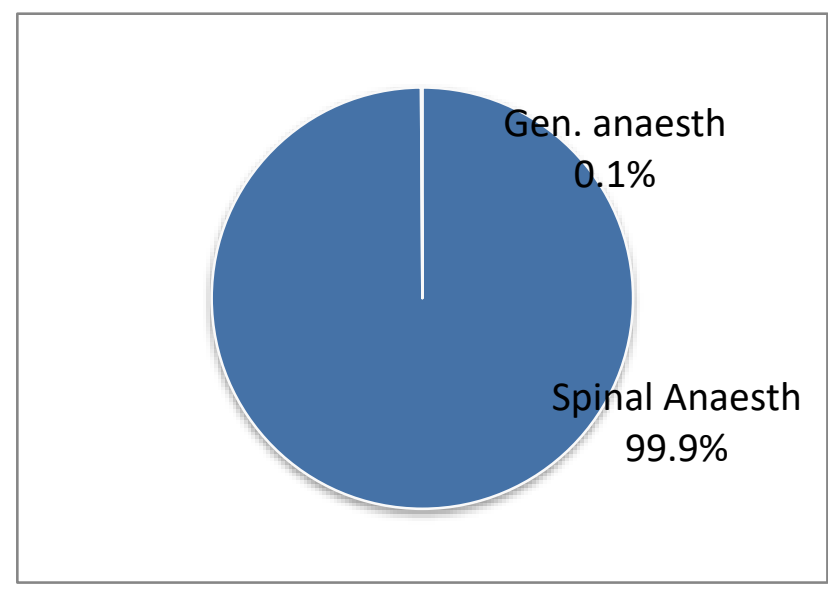

Figure 4: Spinal v/s general anaesthesia.

Ninety-nine-point nine percent of the C-sections have been done under spinal anaesthesia. There was one maternal death in the year 2009.

\section{DISCUSSION}

Caesarean delivery is not the panacea for the obstetrics problems. One should not try to find the solutions for all the obstetrics problems by operating delivery of the foetus. Caesarean delivery should be done in a cautiously chosen patient group; otherwise, there will be unnecessary increase in the operative morbidity from the avoidable C-sections s. RCOG protocol says "the incidence of $\mathrm{C}$-sections should not exceed $20 \%$ in a tertiary care hospital with average labour ward admission of 2000 per year. ${ }^{3}$ Health and family welfare department of India has framed the protocols based on the WHO guidelines which recommends the rate of CS should be between $10-50 \%$ based on the kind and location of hospital, facility and expertise availability. ${ }^{1,2}$ In India Mehta et al reported a raising rate of c- sections from 9$19 \%$ in a less than a decade (1987-1997). ${ }^{7}$ In Kolkata , Saha et al conducted a study and found that $\mathrm{C}$ sections rate increased to $29 \%$ in $2007 .{ }^{8}$ Despite having a proven evidence of the risk related to operative delivery and anaesthesia the rate of $\mathrm{C}$-sections is rising., 5 "Once a caesarean always a caesarean" needs to be remembered when making a decision for caesarean delivery. ${ }^{5}$ Chaudhary et al in their study found that increased maternal age groups are at higher risk of caesarean delivery. ${ }^{9}$

This audit reveals a constant increase in the incidence of C-sections from $16.8 \%$ in 2007 to $51 \%$ in 2012 (Figure 2 and 3). This might be because of regular availability of the experienced obstetrician from the health and family welfare department at this district general hospital or increase referral because due to nonavailability of the obstetrician or the anaesthesiologist or the paediatrician in the peripheral hospitals. This could be also due to better operation theatre and support facilities to manage complex obstetrics emergencies compare to poorly resourced peripheral hospitals. RCOG recommends to not to exceed C-section's rate to more than $20 \%$ and if exceeds suggests to find out the reason by doing an audit. Accepted C-sections rate by WHO is $15-50 \%$. This wide range could be because of the varied socioeconomic situation and resources availability of various countries the WHO represents. So, we cannot really substantiate Csection rate of $51 \%$ in our hospital saying that it complies with WHO guidelines. We wanted to find the ways to reduce the rate of $\mathrm{C}$-sections. RCOG advises for a second opinion by a senior obstetrician before making decision for CS. After an interdepartmental meeting of obstetricians and anaesthesiologists, in the beginning of 2015 we came up with a protocol for C-section selection criteria and a second opinion by a senior obstetrician was made mandatory. In 2014, this hospital was upgraded to medical college teaching hospital. Experienced senior faculties were appointed to the various departments including $\mathrm{OBG}$ and anaesthesia as per the MCI requirement. Availability of a greater number of these senior faculties made the implementation of the CS protocol more effective. After introduction of this protocol, we noticed reduction in the CS rate. ${ }^{8,9}$ At the end of this audit period the CS rate was $23.5 \%$ (Figure 2 and 3) which nearly complied with the RCOG recommended rate of $20 \%$.

Ninety-nine-point nine percent of the C-sections were done under spinal anaesthesia (SA). Out of 3932 only four cases were done under general anaesthesia (Figure 4 and 5). Traditionally general anaesthesia (GA) was thought relatively less safe for the mothers because of 
higher probability of difficult endotracheal intubation and aspiration due to full stomach and also less safe for foetus because of adverse effects of drugs used during conduct of general anaesthesia on neonate. GA is expensive in terms of cost of drugs, gases, equipment compare to spinal anaesthesia. In the developing countries where resource availability is an issue, spinal was preferred to save cost. In addition, conscious mother can witness the baby delivery and can also have skin to skin contact for better mother and baby bonding. In most of the remote places in India due to lack of skilled anaesthetic assistance (technicians or ODP) in operation theatres and the higher risks related to GA as mentioned earlier, anaesthetists generally prefer spinal anaesthesia. All these factors can substantiate the use of SA for majority patients in this audit group.

Only one mother died in 2009 because of postpartum haemorrhage (PPH) who was switched to general anaesthesia from spinal when her condition was deteriorating.

\section{Limitations}

We have not collected data about the antenatal medical state of the mothers; without which it is difficult to correlate the complex pregnancies and increase $\mathrm{C}$-section rate. This could be a limitation of this audit.

\section{CONCLUSION}

Audit results clearly depict a significant raise in the number of $\mathrm{C}$-sections $\mathrm{s}$ in the beginning of the audit period at KRIMS hospital Karwar. A uniform protocol framed based on RCOA and WHO guidelines to have higher threshold for making a decision for $\mathrm{C}$-section and seeking second opinion of a senior obstetrician to aid decision was implemented. This approach has probably made a significant impact in reducing the rate of $\mathrm{C}$ section to an acceptable level. In addition to continuing to implement this protocol, a robust policy to optimize and improve the standards of vaginal delivery with fetal and maternal monitoring with regular review of the labour process will be implemented. A suggestion to hospital administration to provide anaesthesia assistants and a safe environment where anaesthesiologists feel comfortable to conduct general anaesthesia for C-section to be made. A robust protocol to prevent PPH had to be implemented. We have plans to re-audit in 6-12 months period to see the impact of changes implemented.
Funding: No funding sources Conflict of interest: None declared

Ethical approval: The study was approved by the Institutional Ethics Committee

\section{REFERENCES}

1. Standard treatment guidelines obstetrics and gynaecology, Ministry of Health and Family Welfare, Govt. of India: Caesarean sections. 2013;84.

2. WHO Recommendations. Non-clinical interventions to reduce unnecessary caesarean sections. 2018. Available at: https://www.who.int/reproductivehealth/publications/non-clinical-interventions-toreduce-cs/en. Accessed on 3 March 2021.

3. Boyd S. Providing maternity service standards, maternity standards a framework for Maternity service standards Providing quality care for women A framework for Maternity service standards. The Royal College of Obstetricians and Gynaecologists, London. 2016;4-69.

4. Lawn JE, Blencowe H, Oza S, You D, Lee AC, Waiswa $\mathrm{P}$ et al. Every Newborn Study Group: progress, priorities, and potential beyond survival. Lancet. 2014;384(9938):189-205.

5. Turner MJ. Delivery after one previous caesarean section. Am J obstetric gynaecol. 1997;176:174-4.

6. Tollannes MC. Increased rate of caesarean sectionscauses and consequences. TidssKkrser Nor, Laegeforen. 2009;129(13):1329-31.

7. Mehta A, Apers L, Verstraelen H. Trends in caesarean sections in a maternity hospital in Mumbai India. J Health Popular Nutrirt. 2001:19(4):306-12.

8. Saha S, Dar R. A paradigm shift to check the increased caesarean delivery is the need of the hour, but how? J Obstetrics Gynaecol India. 2012;62(4):391-7.

9. Choudhury AP, Dawson AJ. Trends in Indication for caesarean section over 7 years in a Welsh District General Hospital. J Obsteterics Gynaecol. 2009;29(8):714-7.

Cite this article as: Kadur SB, Shetty AB. Changing trends in the incidence of caesarean section after a district hospital became medical college teaching hospital at Karwar, a coastal city in Karnataka-an eleven years retrospective audit. Int J Reprod Contracept Obstet Gynecol 2021;10:2249-52 